\title{
Recovery of Uranium from Seawater: Preparation and Development of Polymer-Supported Extractants
}

\author{
Fuel Cycle R\&D \\ Dr. Spiro Alexandratos \\ CUNY, Hunter College
}

Stephen Kung, Federal POC

Sheng Dai, Technical POC

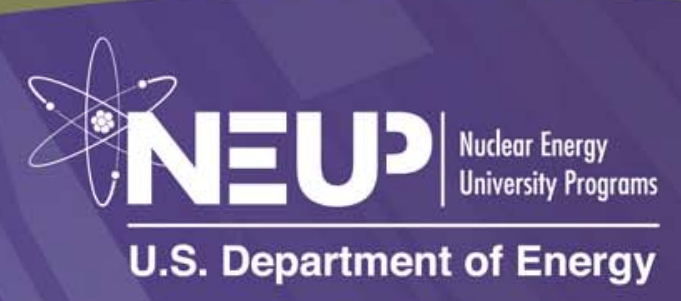




\title{
FINAL REPORT
}

Project Title: $\quad$ Recovery of Uranium from Seawater: Preparation and Development of Polymer-Supported Extractants, 11-3115

Covering Period: $\quad$ October 1, 2011 through September 30, 2013

Date of Report: $\quad$ November 30, 2013

Recipient: Hunter College of the City University of New York

695 Park Avenue

New York, NY 10065

Award Number: 120542

Principal Investigator: Spiro D. Alexandratos, 212 650-3914, alexsd@hunter.cuny.edu

\begin{abstract}
The primary amine $-\mathrm{CH}_{2} \mathrm{NH}_{2}$ ligand bound to cross-linked polystyrene has been discovered to have a high affinity for the uranyl ion from a matrix of artificial seawater. The uranyl capacity is $14.8 \mathrm{mg} \mathrm{U} / \mathrm{g}_{\text {polymer }}$ compared to $2.34 \mathrm{mg} \mathrm{U} / \mathrm{g}_{\text {polymer }}$ for a diamidoxime ligand on a polystyrene support. Secondary and tertiary amines have much lower affinities. The results with polystyrene-bound - $\mathrm{CH}_{2} \mathrm{NH}_{2}$ suggest at least a 3-fold increase in uranyl capacity (calculated on a per mole ligand basis (not per gram of polymer in order to make the results independent of the weight of the polymer support)) and a 4-fold increase when ligands with two primary amines per ligand are utilized. An additional advantage of the primary amine over amidoxime is that it is a simpler ligand to prepare.
\end{abstract}

\section{Results}

Figure 1 shows the structures of the amines whose uranyl capacities were studied. Table 1 gives their nitrogen and acid capacities, and \% dry mass content. The theoretical nitrogen capacities are calculated on the basis of the structures shown in Fig. 1. Comparing the acid to the nitrogen capacity gives the number of amine sites that are in the $\mathrm{HCl}$ form and shows that amines with more than two nitrogens do not exceed two $\mathrm{HCl}$ per ligand. 
Comparing the experimental to the theoretical nitrogen capacities shows that $\mathrm{pA}$ and $\mathrm{pDMA}$ consist only of the expected ligand; pMA crosslinks to the tertiary amine and the remaining amines have various levels of secondary crosslinking since the nitrogen capacities are lower than theoretical. FTIR spectra do not show the $\mathrm{CH}_{2} \mathrm{Cl}$ band at $1265 \mathrm{~cm}^{-1}$ hence the lower nitrogen capacities are not due to incomplete reaction. The \% yield indicates the extent to which the non-crosslinked ligand is produced. pA has the lowest dry mass content and so has the highest hydrophilicity which is consistent with it having the fewest carbons at the amine.
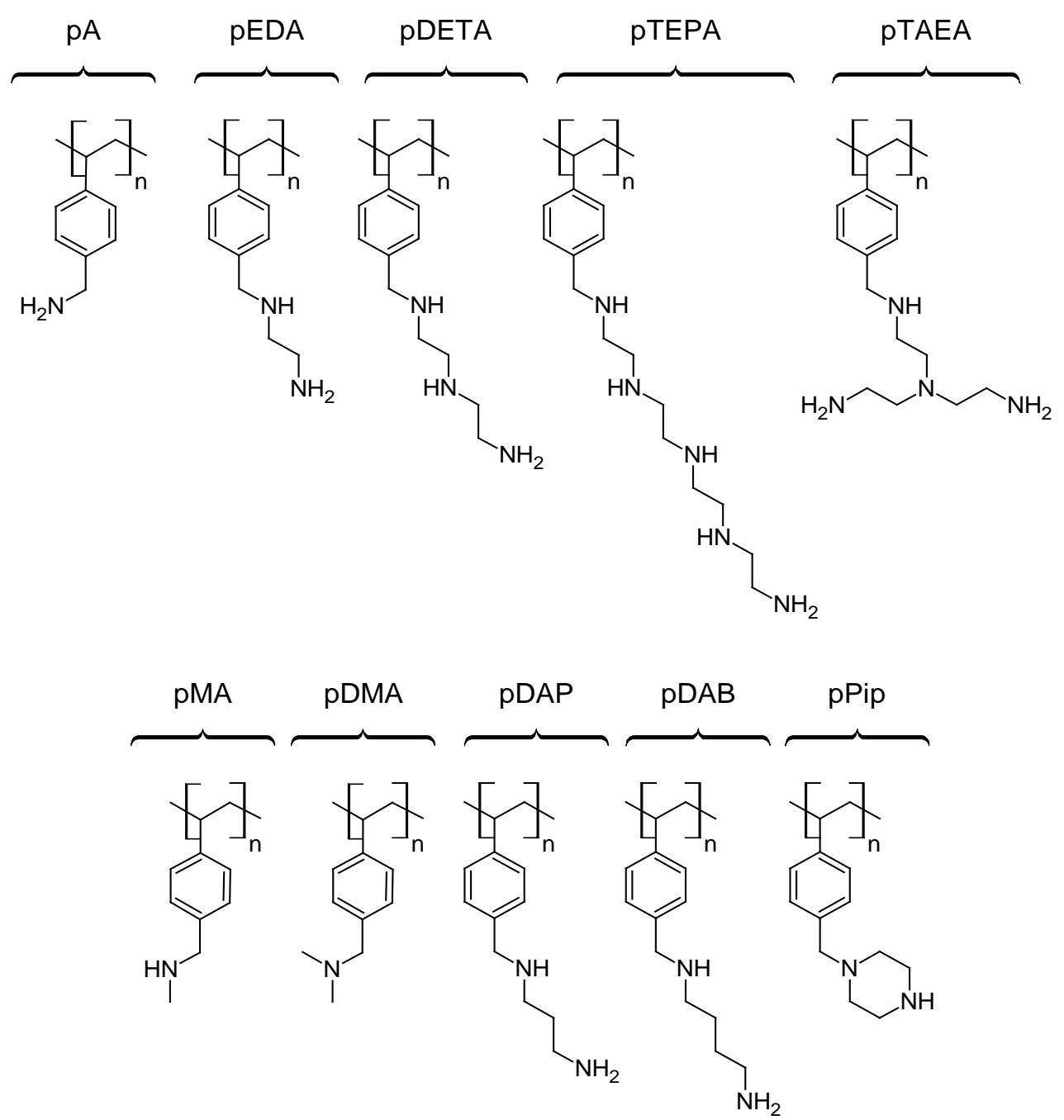

Figure 1. Structures of polymers synthesized. 
Table 1. Physico-chemical properties of the polymers (nitrogen and acid capacities are to \pm 0.2 and the dried mass contents are to $\pm 5 \%$ ).

\begin{tabular}{cccccc} 
& \multicolumn{2}{c}{ N cap. } & Yield & Acid cap. & D.M.C. \\
\cline { 2 - 6 } polymer & \multicolumn{2}{c}{ mmol N / } & \% & mmol H / g & \% \\
\cline { 2 - 6 } pVBC & Exp. & Theor. & & Exp. & \\
\hline pA & - & 0 & - & 5.00 & 100 \\
\hline pMA & 5.46 & 5.71 & 95.6 & 4.88 & 49.3 \\
\hline pDMA & 3.60 & 5.24 & 68.7 & 4.54 & 33.0 \\
\hline pDAP & 4.48 & 4.87 & 92.0 & 5.50 & 33.5 \\
\hline pDAB & 5.56 & 7.32 & 76.0 & 5.37 & 34.4 \\
\hline pEDA & 5.81 & 6.96 & 83.5 & 6.13 & 30.0 \\
\hline pDETA & 6.61 & 7.74 & 85.4 & 5.96 & 33.6 \\
\hline pTEPA & 8.43 & 9.90 & 85.2 & 5.77 & 39.6 \\
\hline pPip & 8.51 & 11.6 & 73.3 & 3.58 & 47.2 \\
\hline pTAEA & 5.30 & 8.06 & 65.8 & 5.17 & 41.6 \\
\hline
\end{tabular}

Table 2 compares the uranyl capacities of the polymers. A much higher capacity is evident for $\mathrm{pA}$ (14.8 $\mathrm{mg} \mathrm{U} / \mathrm{g}_{\text {polymer }}$ ) than pMA and pDMA (0.14 and $0.09 \mathrm{mg} \mathrm{U} / \mathrm{g}_{\text {polymer, }}$ respectively).

Table 2. Uranyl capacities as $\mathrm{mg} \mathrm{U} / \mathrm{g}_{\text {polymer }}$ and $\mathrm{mmolU} / \mathrm{mol}_{\text {ligand }}$ (all runs in duplicate and capacities ( $\mathrm{mg} \mathrm{U} / \mathrm{g}$ ) reproducible to $\pm 5 \%$ ).

\begin{tabular}{cccc}
\multirow{2}{*}{ Resin } & U capacity & N capacity & U capacity \\
\cline { 2 - 4 } pVBC & $\mathrm{mg} \mathrm{U} / \mathrm{g}_{\text {polymer }}$ & $\mathrm{mmol} \mathrm{N} / \mathrm{g}_{\text {polymer }}$ & $\mathrm{mmol} \mathrm{U} / \mathrm{mol}_{\text {ligand }}$ \\
\hline pDMA & 0 & - & 0 \\
\hline pMA & 0.09 & 4.48 & 0.084 \\
\hline pPip & 0.14 & 3.60 & 0.165 \\
\hline pDAP & 0.97 & 5.30 & 1.54 \\
\hline pDAB & 6.05 & 5.56 & 9.14 \\
\hline pA & 6.62 & 5.81 & 9.57 \\
\hline pEDA & 14.8 & 5.46 & 11.4 \\
\hline pDETA & 10.4 & 6.61 & 13.2 \\
\hline pTEPA & 8.89 & 8.43 & 13.3 \\
\hline pTAEA & 7.17 & 8.51 & 17.7 \\
\hline
\end{tabular}

The primary amine thus has a high affinity for the uranyl ion from seawater and complexation is sensitive to substituents at the amine nitrogen. All polymers with primary amine groups have a significant capacity for uranyl from seawater. (Note these are loadings from an initial solution of $50 \mathrm{mg} / \mathrm{L}$ and are not to be considered saturation capacities.) 


\section{Discussion}

Comparison of capacities. The uranyl capacities for pDAP and pDAB seem lower than for $\mathrm{pA}$, and there seems to be a decrease in capacity along the series pA, pEDA, pDETA, and pTEPA. However, a direct comparison of all polymers on a per gram basis is problematic since the molecular weight of the monomer unit changes as the ligand structure changes. A comparison on the basis of the nitrogen capacity is more useful. Converting $\mathrm{mg} \mathrm{U} / \mathrm{g}$ polymer to mmol $\mathrm{U} /$ mol $_{\text {ligand }}$ allows for a more meaningful comparison of the ligands' inherent affinities on a molar basis. Table 2 reports the affinities on a per gram and per mole basis in order to indicate that high affinities are achieved with relatively low-mass ligands (a high-affinity ligand coupled to a high mass is not useful since the final polymer to be deployed must be of low total weight). The results in Table 2 underscore the significance of the primary amine to the removal of uranium from seawater. The $\mathrm{pA}$ value is still high $\left(11.4 \mathrm{mmol} U / \mathrm{mol}_{\text {ligand }}\right)$ while pDAP and pDAB have

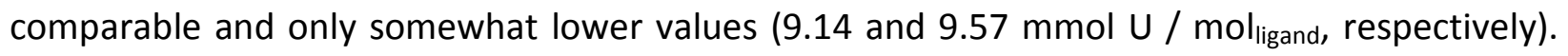
pEDA and pDETA are now seen to have the same capacities (13.2 and $13.3 \mathrm{mmol} \mathrm{U} / \mathrm{mol}$ ligand, respectively). pTEPA has a still higher value $\left(17.7 \mathrm{mmol} \mathrm{U} / \mathrm{mol}_{\text {ligand }}\right)$ that is almost equivalent to

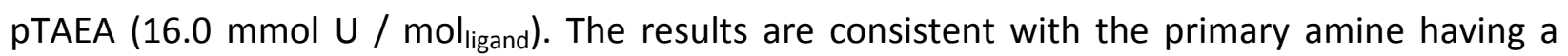
high affinity for the uranyl ion from seawater: TEPA immobilization occurs to some extent through one of the interior nitrogens giving two primary amines per ligand while TAEA inevitably gives two primary amines per ligand.

Comparison with amidoxime. It is relevant to compare the results reported in Table 2 with the amidoxime ligand in order to gauge the relative affinities of the primary amine and amidoxime ligands. The highest capacity attained for the amidoxime from seawater is $4 \mathrm{mg} \mathrm{U} / \mathrm{g}_{\text {polymer }}$ with the ligand on polyethylene fibers. ${ }^{1}$ A comparison with $\mathrm{pA}$ (14.8 $\mathrm{mg} \mathrm{U} / \mathrm{g}_{\text {polymer }}$ ) is problematic, however, because of the higher monomer molecular weight for the latter and the difference in initial solution uranyl levels (actual seawater in the former, spiked artificial seawater in the latter for analytical purposes). A more valid comparison would be between the values in Table 2 with amidoxime bound to the same polymer support and the same initial solution conditions. While the monoamidoxime is difficult to prepare on polystyrene, the diamidoxime has been 
prepared (Fig. 2). It has a uranyl capacity of $2.34 \mathrm{mg} \mathrm{U} / \mathrm{g}_{\text {polymer }}$. With a nitrogen capacity of 10.4 $\mathrm{mmol} / \mathrm{g}$, this recalculates to $3.79 \mathrm{mmol} \mathrm{U} / \mathrm{mol}_{\text {ligand. }}$. Since the diamidoxime has a higher uranyl affinity than the monoamidoxlme, ${ }^{2}$ the results reported here with pA suggest at least a 3-fold increase in uranyl capacity by the primary amine ligand (calculated on a mole basis) and a 4-fold increase when ligands with two primary amines per ligand are utilized.

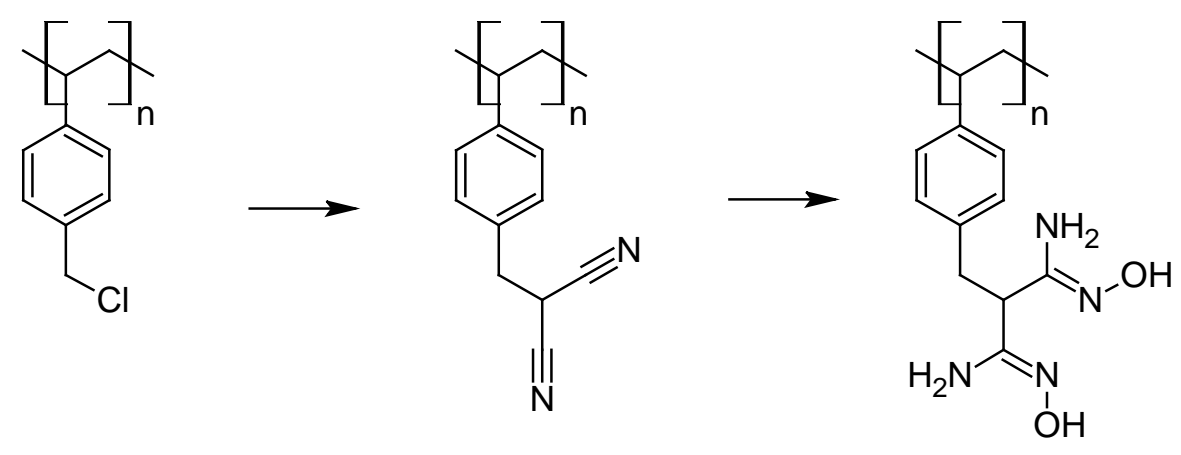

Figure 2. Polystyrene-bound diamidoxime prepared from immobilized malononitrile.

Binding Mechanism. The binding mechanism must account for the significantly higher affinity of the primary amine relative to secondary and tertiary amines. The conditions in seawater are such that the uranyl species ${ }^{3}$ are primarily $\mathrm{UO}_{2}\left(\mathrm{CO}_{3}\right)_{2}{ }^{2-}$ and $\mathrm{UO}_{2}\left(\mathrm{CO}_{3}\right)_{3}{ }^{4-}$ and that they exist mostly as the calcium salt. ${ }^{4}$ The amines are protonated at seawater $\mathrm{pH}$ with chloride as the counterions. ${ }^{5}$ Given these conditions, it is proposed that the sorption mechanism is one of cation exchange at the uranyl species (Fig. 3).

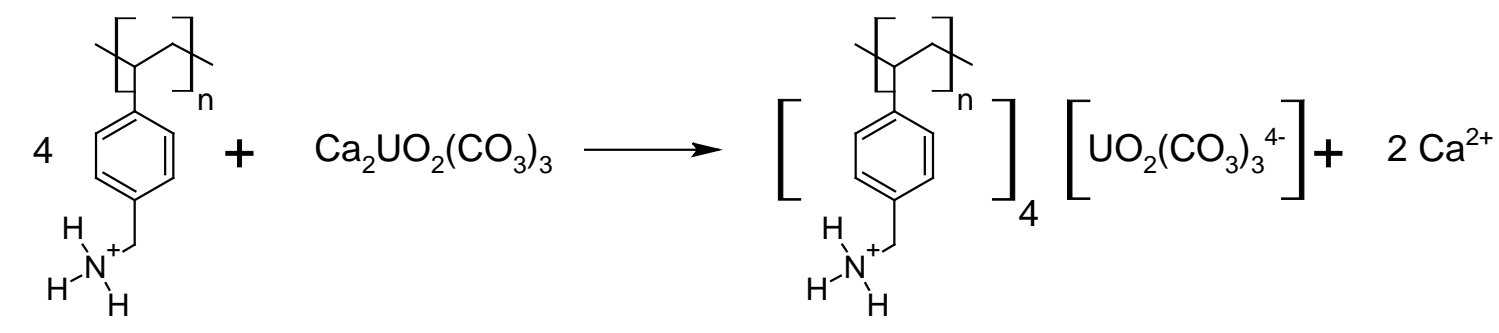

Figure 3. Sorption of uranyl from seawater by the primary amine via cation exchange.

An analogous reaction is the formation as a precipitate of ammonium uranyl carbonate from the combination of ammonium and uranyl carbonate ions (eq. 1). 


$$
4 \mathrm{NH}_{4}^{+}+\left[\mathrm{UO}_{2}\left(\mathrm{CO}_{3}\right)_{3}\right]_{\text {sol }}^{4-} \rightarrow\left[\mathrm{NH}_{4}^{+}\right]_{4}\left[\mathrm{UO}_{2}\left(\mathrm{CO}_{3}\right)_{3}\right]_{S}
$$

In the present case, the binding site is the carbonate ion as the ammonium ion exchanges with the calcium. Carbonate is a hard anion ${ }^{6}$ and the exchange requires ammonium $\left(-\mathrm{NH}_{3}{ }^{+}\right)$to be harder than calcium. This is supported by the observation that the $\mathrm{NH}_{4}{ }^{+}$ion exchanges onto aluminosilicates in preference to $\mathrm{Ca}^{2+}, \mathrm{Mg}^{2+}$ and $\mathrm{K}^{+}$. Consideration of the hard-soft aspect of the exchange is also consistent with the absence of significant activity by the secondary and tertiary amines: increasing the organophilicity at the nitrogen increases the softness of the ammonium ligand ${ }^{8}$ and thus decreases their affinity for the hard carbonate complex.

\section{Conclusions}

The primary amine is found to have a dominant effect on the sorption of uranyl from seawater. This could become important in the preparation of sorbents with high uranyl capacities under seawater conditions. The extent of complex formation is limited by the decreasing probability of formation as molecularity increases. Such a limitation could be overcome by immobilizing ligands with a high density of primary amine sites. Mobility of the primary amine sites also appears crucial to allow the formation of the corresponding complexes around the equatorial plane of the uranyl cation or carbonate complex.

Current research is focused on increasing the uranyl capacity by increasing the primary amine density on new ligand structures involving pentaerythritol as a scaffold as well as immobilizing amines on polypropylene fiber.

\section{References}

(1) Kim, J.; Oyola, Y.; Mayes, R.; Janke, C.; Dai, S.; Tsouris, C. In Testing of Amidoxime-Based Adsorbent for the Recovery of Uranium From Seawater, AIChE Annual Meeting.

(2) Kavakli, P.; Seko, N.; Tamada, M.; Goven, O. A Highly Efficient Chelating Polymer for the Adsorption of Uranyl and Vanadyl lons at Low Concentrations. Adsorption 2005, 10, 309-315.

(3) Pashalidis, I.; Czerwinski, K. R.; Fanghanel, T.; Kim, J. I. Solid-liquid phase equilibria of Pu(VI) and U(VI) in aqueous carbonate systems. Determination of stability constants. Radiochimica Acta 1997, 76, 55-62. 
(4) Dong, W.; Brooks, S. C. Determination of the Formation Constants of Ternary Complexes of Uranyl and Carbonate with Alkaline Earth Metals (Mg2+, $\mathrm{Ca} 2+, \mathrm{Sr} 2+$, and $\mathrm{Ba} 2+$ ) Using Anion Exchange Method. Environmental Science \& Technology 2006, 40, 4689-4695.

(5) Smith, R. M.; Martell, A. E., Critical Stability Constants, Vol. 2: Amines. Plenum: 1975; p 415.

(6) Martin, R. B. Practical hardness scales for metal ion complexes. Inorganica Chimica Acta 2002, 339, 27-33.

(7) Weatherley, L. R.; Miladinovic, N. D. Comparison of the ion exchange uptake of ammonium ion onto New Zealand clinoptilolite and mordenite. Water Research 2004, 38, 4305-4312.

(8) Bonnesen, P. V.; Brown, G. M.; Alexandratos, S. D.; Bavoux, L. B.; Presley, D. J.; Patel, V.; Ober, R.; Moyer, B. A. Development of Bifunctional Anion-Exchange Resins with Improved Selectivity and Sorptive Kinetics for Pertechnetate: Batch-Equilibrium Experiments. Environmental Science \& Technology 2000, 34, 3761-3766.

\section{$\mid / / / / / / / / / / / / / / / / /$}

The original proposal had a three-year timetable for Milestones and Deliverables but the work was funded for the two-year period of which this report is the result. As required by the conditions of the award, a comparison is made between the Milestones and Deliverables and the accomplishments of this work.

NOTE: The proposal was written with the expectation that the ligand of choice for uranyl recovery would be the phosphonate ligand. This work, however, uncovered the fact that the amine ligand has a very high affinity for the uranyl ion from seawater and it became the focus of this two-year period.

I. Identify a phosphonate whose affinity for $\mathrm{UO}_{2}{ }^{2+}$ from synthetic seawater is $50 \%$ greater than that of amidoxime.

ACCOMPLISHED: an amine ligand was identified whose affinity for $\mathrm{UO}_{2}{ }^{2+}$ is $300 \%$ greater than that of amidoxime (under synthetic seawater conditions)

II. Prepare a phosphonate (in the form of beads) whose sorption rate for $\mathrm{UO}_{2}{ }^{2+}$ is $50 \%$ greater than amidoxime.

ACCOMPLISHED: An amine was prepared in the form of beads whose sorption rate for $\mathrm{UO}_{2}{ }^{2+}$ is at least $50 \%$ greater than amidoxime (also in the form of beads)

III. Compare the performances of the best phosphonates with amidoxime; identify a phosphonate whose sorption characteristics, including rate of sorption, are $50 \%$ better than the amidoxime.

ACCOMPLISHED: The primary amine $-\mathrm{CH} 2 \mathrm{NH} 2$ has been identified as performing significantly better that the amidoxime under all conditions tested 
IV. Identify a phosphonate whose stability in repeated loading / regeneration cycles outperforms that of amidoxime.

ACCOMPLISHED: The primary amine ligand readily regenerates and is reusable.

V. Prepare a polypropylene fiber where grafting with polyVBC via $\mathrm{scCO}_{2}$ technology is superior in terms of support degradation and homopolymer formation relative to irradiation technology.

ACCOMPLISHED: Conditions have been identified where polyVBC grafts onto polypropylene fiber with no support degradation whatsoever.

VI. Deliver a polypropylene fiber functionalized with the optimum phosphonate ligand that outperforms the best available amidoxime-bearing fiber in uranyl loading under actual seawater conditions.

NOT ACCOMPLISHED: While there is every expectation that the polyVBC can be converted to amine and that it will have at least the same performance characteristics of the beads, the award period ended before this could be studied.

DELIVERABLES: A sample of the beads functionalized with the primary amine ligand was delivered to PNNL for testing under authentic seawater conditions; their results are pending.

\section{PUBLICATION}

Sellin, R.; Alexandratos, S.D. Industrial \& Engineering Chemistry Research, 2013, 52, 11792 11797.

\section{PRESENTATION}

Sellin, R.; Alexandratos, S.D. $244^{\text {th }}$ National Meeting of the American Chemical Society, Polymer-Supported Reagents for the Extraction of Uranium from Seawater, Symposium on Extraction of Uranium from Seawater; Abstracts, American Chemical Society, Philadelphia: 2012 


\title{
Polymer-Supported Primary Amines for the Recovery of Uranium from Seawater
}

\author{
Remy Sellin and Spiro D. Alexandratos* \\ Department of Chemistry, Hunter College of the City University of New York, 695 Park Avenue, New York, New York 10065, \\ United States
}

\begin{abstract}
The primary amine $-\mathrm{CH}_{2} \mathrm{NH}_{2}$ ligand bound to cross-linked polystyrene has a high affinity for the uranyl ion from a matrix of artificial seawater. The uranyl capacity is $14.8 \mathrm{mg} \mathrm{U} / \mathrm{g}_{\text {polymer }}$, compared to $2.34 \mathrm{mg} \mathrm{U} / \mathrm{g}_{\text {polymer }}$ for a diamidoxime ligand on a polystyrene support. Secondary and tertiary amines have much lower affinities, indicating that steric effects are important to the complexation. The results with polystyrene-bound $-\mathrm{CH}_{2} \mathrm{NH}_{2}$ thus suggest at least a 3-fold increase in uranyl capacity (calculated on a per mole ligand basis (not per gram of polymer, in order to make the results independent of the weight of the polymer support)) and a 4-fold increase when ligands with two primary amines per ligand are utilized. An additional advantage of the primary amine over amidoxime is that it is a simpler ligand to prepare.
\end{abstract}

\section{INTRODUCTION}

The total amount of uranium available in global seawater is estimated to be 4.5 billion tons, despite its extremely low concentration of $3.3 \mathrm{ppb}^{1}$ Recovery of this uranium could produce nuclear energy for centuries, thus solving the problem of the known low reserves available from terrestrial ores. Because of its rarity in the terrestrial crust $(0.91 \mathrm{ppm})$, uranium recovery from seawater has been considered since the early 1950 s as a potential resource. Different solid sorbents have been developed, including various inorganic and organic materials. ${ }^{1}$

Since the concentration of uranium is so low within a seawater matrix that is a complex mixture of cations and anions, the ideal material for its recovery must meet several criteria. A high affinity for the uranyl cation is important because it is bound to the carbonate ion in seawater. This is a nontrivial target to achieve, since it is the carbonate ion that solubilizes the uranium and the tricarbonate complex has a high stability constant. $^{2}$ By way of comparison, the complexation of uranyl from nitrate by polystyrene-bound phosphonic acid has a uranyl capacity of $175 \mathrm{mg} \mathrm{U} / \mathrm{g}_{\text {polymer}}$, which is a much higher amount than possible from seawater (see below). ${ }^{3}$ The sorbent must also have the following characteristics: high selectivity for uranyl in the presence of calcium, magnesium, and other cations; a high loading capacity; high sorption and desorption rates; low manufacturing cost; and a high chemical stability in the seawater $\mathrm{pH}$ range of $7.4-9.6 .{ }^{4} \mathrm{~A}$ high sorption rate is important when considering the possibility of biofouling during prolonged exposure to the sea. Stability under sorptiondesorption cycling is also required to minimize the cost of the extraction process by increasing the lifetime of the sorbent.

Decades of research in this area have been focused on immobilized amidoxime ligands. ${ }^{5,6}$ The polymer is often prepared by grafting acrylonitrile to polypropylene fibers and subsequent conversion of the nitrile to amidoxime. It provides the benchmark for loading capacity from seawater, often cited as $4 \mathrm{mg} \mathrm{U} / \mathrm{g}_{\text {polymer }}$. However, the efficiency of amidoximes decreases with sorption-elution cycles for reasons related to the stability of the chemical structures involved but not yet fully understood. ${ }^{5,7}$ Moreover, amidoxime synthesis involves multistep processes, thus increasing the total cost of the final extraction.

The approach taken in this first phase of our research was to study polymer-supported amines as sorbents for uranium from seawater. Polyamines are reported to have good affinity for uranium from neutral ${ }^{8}$ and acidic solutions, ${ }^{9-12}$ as well as seawater conditions. ${ }^{13,14}$ High complexation constants of linear polyamine with the uranyl cation have also been reported from aqueous carbonate-free solutions, ${ }^{2,15}$ due perhaps to coordination of the uranyl cation by nitrogen-containing ligands along its equatorial plane. ${ }^{16}$

\section{EXPERIMENTAL SECTION}

Materials. Vinylbenzyl chloride (96\%), divinylbenzene (55\%), benzoyl peroxide (97\%), calcium chloride dihydrate, anhydrous potassium carbonate, anhydrous sodium carbonate, sodium chloride, potassium phthalimide (99\%), hydrazine monohydrate $(80 \%)$, ethylenediamine (EDA), diethylenetriamine (DETA), tetraethylenepentamine (TEPA), N-tris(2aminoethyl)amine (TAEA), 1,3-diaminopropane (DAP), and 1,4-diaminobutane (DAB) were purchased from Acros. $\mathrm{N}$ methylpyrrolidone (NMP), ethanol, and tetrahydrofuran (THF) were purchased from Fisher. Deionized water with $18.2 \mathrm{M} \Omega \mathrm{cm}^{-1}$ resistivity was used from a Nanopure system (Barnstead). Artificial seawater prepared with ASTM D1141 composition was purchased from Ricca. The precise composition ${ }^{17}$ includes $\mathrm{NaCl}(24.53 \mathrm{~g} / \mathrm{L}), \mathrm{MgCl}_{2}(5.20 \mathrm{~g} / \mathrm{L})$, $\mathrm{Na}_{2} \mathrm{SO}_{4}(4.09 \mathrm{~g} / \mathrm{L}), \mathrm{CaCl}_{2}(1.16 \mathrm{~g} / \mathrm{L}), \mathrm{KCl}(0.695 \mathrm{~g} / \mathrm{L})$, and $\mathrm{NaHCO}_{3}(0.201 \mathrm{~g} / \mathrm{L})$.

Synthesis of Poly(vinylbenzyl chloride). Poly(vinylbenzyl chloride) gel beads ( $\mathrm{pVBC}$ ) were prepared by suspension polymerization of vinylbenzyl chloride (VBC) and 2

Received: June 23, 2013

Revised: July 18, 2013

Accepted: July 30, 2013

Published: July 30, 2013 
wt \% divinylbenzene (DVB) following a procedure described elsewhere. ${ }^{18}$ The beads were extracted with toluene for $17 \mathrm{~h}$, dried, and sieved using U.S. standard screens. The particle size used for all syntheses was $250-500 \mu \mathrm{m}$.

Synthesis of Poly(vinylbenzyl amine) (pA). The pVBC beads were converted to poly(vinylbenzyl amine) via the Gabriel synthesis. ${ }^{19}$ The beads were conditioned with 1-L elutions of $1 \mathrm{~N} \mathrm{NaOH}$, deionized water, $1 \mathrm{~N} \mathrm{HCl}$, and deionized water.

Synthesis of Immobilized $N$-methylamine (pMA). The pVBC beads were converted to pMA via nucleophilic substitution: $100 \mathrm{~mL}$ of a 40 wt \% aqueous methylamine solution was stirred with $8 \mathrm{~g}$ of $\mathrm{pVBC}$ in $100 \mathrm{~mL}$ of NMP at 23 ${ }^{\circ} \mathrm{C}$ for $17 \mathrm{~h}$, then $70{ }^{\circ} \mathrm{C}$ for $2 \mathrm{~h}$. The resulting beads were conditioned as above.

Synthesis of Immobilized $\mathrm{N}, \mathrm{N}$-dimethylamine (pDMA). The pVBC beads were converted to pDMA by stirring $50 \mathrm{~mL}$ of a $40 \mathrm{wt} \%$ aqueous dimethylamine solution with $4 \mathrm{~g}$ of pVBC in $100 \mathrm{~mL}$ of dioxane at reflux for $17 \mathrm{~h}$. The resulting beads were conditioned as above.

Synthesis of Immobilized Diaminopropane (pDAP). The pVBC beads were converted to pDAP by stirring $20 \mathrm{~mL}$ of 1,3-diaminopropane with $4 \mathrm{~g}$ of $\mathrm{pVBC}$ in $150 \mathrm{~mL}$ of THF at 50 ${ }^{\circ} \mathrm{C}$ for $17 \mathrm{~h}$. The resulting beads were conditioned as above.

Synthesis of Immobilized Diaminobutane (pDAB). The pVBC beads were converted to $\mathrm{pDAB}$ by stirring $25 \mathrm{~mL}$ of 1,4-diaminobutane with $4 \mathrm{~g}$ of $\mathrm{pVBC}$ in $150 \mathrm{~mL}$ of THF at $50{ }^{\circ} \mathrm{C}$ for $17 \mathrm{~h}$. The resulting beads were conditioned as above.

Synthesis of Immobilized Ethylenediamine (pEDA). The pVBC beads were converted to pEDA by stirring $40 \mathrm{~mL}$ of ethylenediamine with $2.0 \mathrm{~g}$ of $\mathrm{pVBC}$ and $1.2 \mathrm{~g}$ of potassium carbonate in $110 \mathrm{~mL}$ of THF at $50{ }^{\circ} \mathrm{C}$ for $17 \mathrm{~h}$. The resulting beads were conditioned as above.

Synthesis of Immobilized Diethylenetriamine (pDETA). The pVBC beads were converted to pDETA by stirring $75 \mathrm{~mL}$ of diethylenetriamine with $2.0 \mathrm{~g}$ of $\mathrm{pVBC}$ and $1.2 \mathrm{~g}$ of potassium carbonate in $165 \mathrm{~mL}$ of THF at $50^{\circ} \mathrm{C}$ for 17 h. The resulting beads were conditioned as above.

Synthesis of Immobilized Tetraethylenepentamine (pTEPA). The procedure followed that of the pDETA, except that $120 \mathrm{~mL}$ of TEPA and $300 \mathrm{~mL}$ of THF were used.

Synthesis of Immobilized Piperazine (pPIP). The pVBC beads were converted to $\mathrm{pPIP}$ by stirring $23.3 \mathrm{~g}$ of piperazine dihydrate with $4 \mathrm{~g}$ of $\mathrm{pVBC}$ at $65^{\circ} \mathrm{C}$ for $17 \mathrm{~h}$ using a mixture of $135 \mathrm{~mL}$ of dioxane and $20 \mathrm{~mL}$ of water as solvent. The resulting beads were conditioned as above.

Synthesis of Immobilized $\mathbf{N}$-tris(2-aminoethyl)amine (pTAEA). The polyVBC beads were converted to pTAEA by stirring $10 \mathrm{~mL}$ of tris(2-aminoethyl)amine with $2 \mathrm{~g}$ of $\mathrm{pVBC}$ in $100 \mathrm{~mL}$ of dioxane at $50{ }^{\circ} \mathrm{C}$ for $17 \mathrm{~h}$. The resulting beads were conditioned as above.

Synthesis of Immobilized Diamidoxime. Adapting a known procedure, ${ }^{20} 24 \mathrm{~g}$ of malononitrile and $14.8 \mathrm{~g}$ of a $60 \mathrm{wt}$ $\% \mathrm{NaH}$ suspension in oil were stirred in $100 \mathrm{~mL}$ THF for $1 \mathrm{~h}$ at $60{ }^{\circ} \mathrm{C}$. polyVBC $(6 \mathrm{~g})$ swollen in $100 \mathrm{~mL}$ of THF was added, and the mixture stirred at $60{ }^{\circ} \mathrm{C}$ for $17 \mathrm{~h}$. The polymer was then washed three times with $100 \mathrm{~mL}$ THF, once with $100 \mathrm{~mL}$ of THF-water (1:1) and three times with $100 \mathrm{~mL}$ of THF. The beads were dried under vacuum for $2 \mathrm{~h}$. The polymer $(4 \mathrm{~g})$ was contacted with $25 \mathrm{~g}$ of hydroxylamine chloride and $18.9 \mathrm{~g}$ of anhydrous $\mathrm{Na}_{2} \mathrm{CO}_{3}$ under $\mathrm{N}_{2}$ for $17 \mathrm{~h}$ at $80{ }^{\circ} \mathrm{C}$ in $100 \mathrm{~mL}$ of 1:1 (v/v) NMP: $\mathrm{H}_{2} \mathrm{O}$. After removing the solvent, the beads were washed with deionized water before conditioning as above.

Characterization. The nitrogen capacities of the polymers were determined by a modified Kjeldahl protocol. ${ }^{21}$ The acid capacities were determined by titration of a $10-\mathrm{mL}$ aliquot from $50 \mathrm{~mL}$ of $0.1000 \mathrm{~N} \mathrm{NaOH}$ solution equilibrated overnight with $500 \mathrm{mg}$ of wet polymer in the $\mathrm{HCl}$ form. The dry mass content (DMC) was determined by drying $200 \mathrm{mg}$ of wet polymer at $110{ }^{\circ} \mathrm{C}$ for $17 \mathrm{~h}$ and calculating the ratio of dry to wet weight. The results are summarized in Table 1. Fourier transform infrared (FTIR) spectra were gathered using $\mathrm{KBr}$ pellets on a Perkin-Elmer Spectrum 65 system.

Table 1. Physico-chemical Properties of the Polymers ${ }^{a}$

\begin{tabular}{|c|c|c|c|c|c|}
\hline \multirow[b]{2}{*}{ polymer } & \multicolumn{2}{|c|}{$\begin{array}{c}\text { Nitrogen } \\
\text { Capacity } \\
(\mathrm{mmol} \mathrm{N} / \mathrm{g})\end{array}$} & \multirow{2}{*}{$\begin{array}{l}\text { yield } \\
(\%)\end{array}$} & \multirow{2}{*}{$\begin{array}{c}\begin{array}{c}\text { Acid Capacity } \\
(\mathrm{mmol} \mathrm{H} / \mathrm{g})\end{array} \\
\exp \end{array}$} & \multirow{2}{*}{$\begin{array}{l}\text { dry mass content, } \\
\text { DMC (\%) }\end{array}$} \\
\hline & $\exp$ & theor & & & \\
\hline $\mathrm{pVBC}$ & & 0 & & & 100 \\
\hline $\mathrm{pA}$ & 5.46 & 5.71 & 95.6 & 5.00 & 18.6 \\
\hline pMA & 3.60 & 5.24 & 68.7 & 4.88 & 49.3 \\
\hline pDMA & 4.48 & 4.87 & 92.0 & 4.54 & 33.0 \\
\hline pDAP & 5.56 & 7.32 & 76.0 & 5.50 & 33.5 \\
\hline $\mathrm{pDAB}$ & 5.81 & 6.96 & 83.5 & 5.37 & 34.4 \\
\hline pEDA & 6.61 & 7.74 & 85.4 & 6.13 & 30.0 \\
\hline pDETA & 8.43 & 9.90 & 85.2 & 5.96 & 33.6 \\
\hline pTEPA & 8.51 & 11.6 & 73.3 & 5.77 & 39.6 \\
\hline pPIP & 5.30 & 8.06 & 65.8 & 3.58 & 47.2 \\
\hline pTAEA & 7.10 & 11.5 & 61.7 & 5.17 & 41.6 \\
\hline
\end{tabular}

${ }^{a}$ Nitrogen and acid capacities are accurate to \pm 0.2 , and the DMC values are accurate to $\pm 5 \%$.

Uranyl Capacities. Polymer conditioned to the $\mathrm{HCl}$ form $(50 \mathrm{mg})$ was weighed, placed into a $20-\mathrm{mL}$ vial, and contacted with successive $20-\mathrm{mL}$ aliquots of artificial seawater until an equilibrium $\mathrm{pH}$ value of 8 was attained. The polymer was then contacted with a 5-mL aliquot of uranyl in artificial seawater at an initial concentration $C_{0}$ of $50 \mathrm{mg} \mathrm{U} / \mathrm{L}$ and shaken for $72 \mathrm{~h}$ at $23{ }^{\circ} \mathrm{C}$. The uranyl equilibrium concentration at equilibrium $C_{\mathrm{eq}}$ was determined on a Perkin-Elmer Optima 7000 DV inductively coupled plasma-optical emission spectrometry (ICP-OES) system. Analysis was performed on the equilibrium solutions diluted 10 -fold with 2 wt $\%$ nitric acid. The calibration curve was determined using standard solutions in artificial seawater with $1,2,5,10,20$, and $50 \mathrm{mg} \mathrm{U} / \mathrm{L}$ diluted 10 -fold with 2 wt \% nitric acid. The equilibrium $\mathrm{pH}$ was also recorded. The uranyl capacity was calculated using the formula

$$
\text { uranyl capacity }=\frac{V\left(C_{0}-C_{\mathrm{eq}}\right)}{m}
$$

where $V$ is the volume and $m$ is the dry mass (dry mass = DMC $X$ wet mass).

\section{RESULTS}

Figure 1 shows the structures of the amines whose uranyl capacities are being reported. Table 1 gives their nitrogen and acid capacities, and dried mass content (DMC) percentage. The theoretical nitrogen capacities are calculated on the basis of the structures shown in Figure 1. Comparing the acid capacity to the nitrogen capacity gives the number of amine sites that are in the $\mathrm{HCl}$ form and this is included in calculating the 

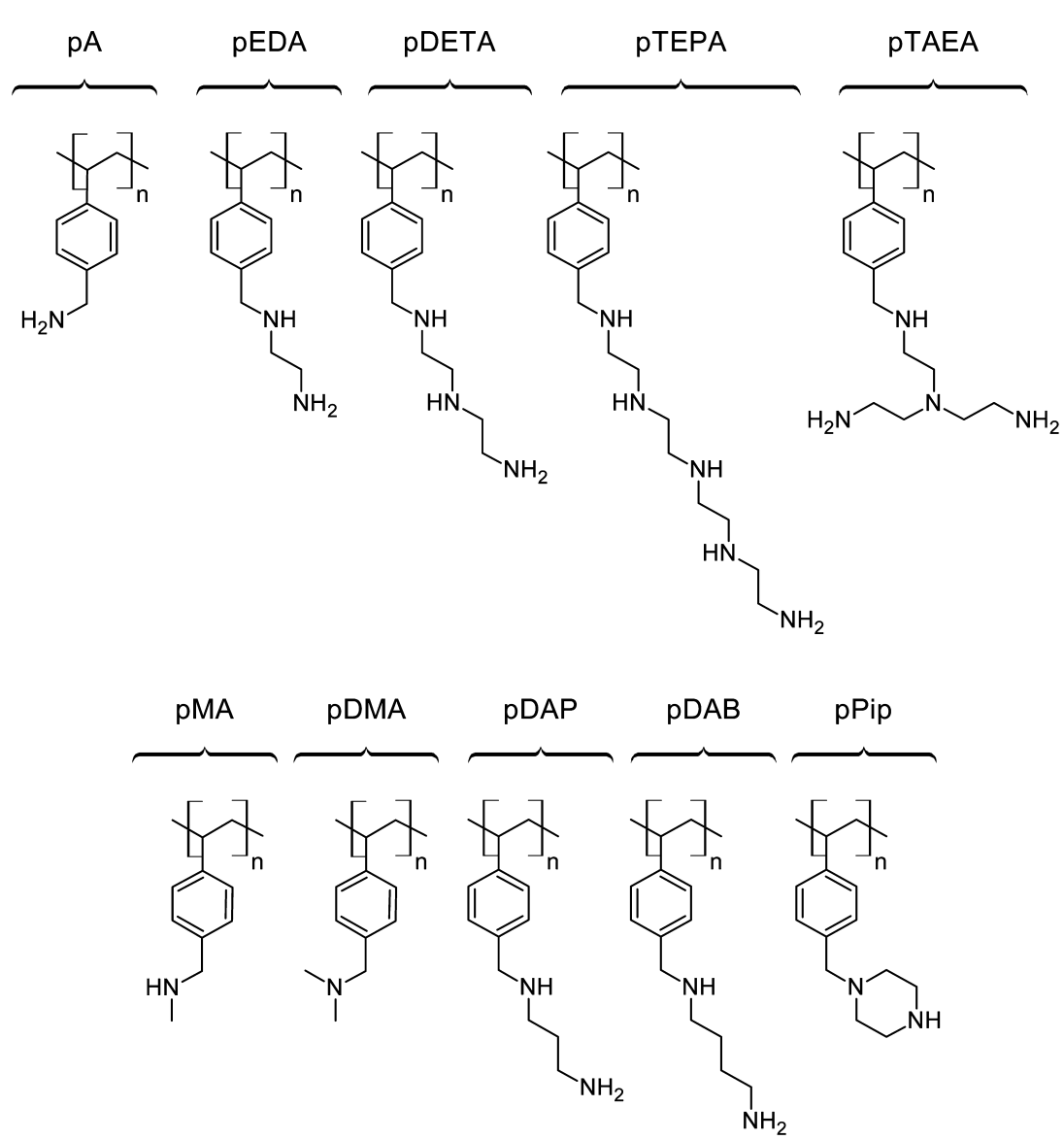

Figure 1. Structures of polymers synthesized.

theoretical nitrogen capacity. Amines with more than two nitrogens do not exceed two $\mathrm{HCl}$ per ligand.

Comparing the experimental to the theoretical nitrogen capacities shows that $\mathrm{pA}$ and $\mathrm{pDMA}$ consist only of the expected ligand; pMA cross-links to the tertiary amine and the remaining amines have various levels of secondary cross-linking since the nitrogen capacities are lower than theoretical. FTIR spectra do not show the $\mathrm{CH}_{2} \mathrm{Cl}$ band at $1265 \mathrm{~cm}^{-1}$; hence, the lower nitrogen capacities are not due to incomplete reaction. The percent yield indicates the extent to which the non-crosslinked ligand is produced. pA has the lowest DMC and therefore has the highest hydrophilicity, which is consistent with it having the fewest carbons at the amine site.

Table 2 compares the uranyl capacities of the polymers. A much-higher capacity is evident for $\mathrm{pA}\left(14.8 \mathrm{mg} \mathrm{U} / \mathrm{g}_{\text {polymer }}\right)$ than pMA and pDMA (0.14 and $0.09 \mathrm{mg} \mathrm{U} / \mathrm{g}_{\text {polymer }}$, respectively).

Therefore, the primary amine has a high affinity for the uranyl ion from seawater and complexation is sensitive to substituents at the amine nitrogen. All polymers with primary amine groups have a significant capacity for uranyl from seawater. [Note that these are loadings from an initial solution of $50 \mathrm{mg} / \mathrm{L}$ and are not to be considered saturation capacities.]

\section{DISCUSSION}

Comparison of Capacities. The uranyl capacities for $\mathrm{pDAP}$ and $\mathrm{pDAB}$ seem lower than for $\mathrm{pA}$, and there seems to be a decrease in capacity along the series $\mathrm{pA}, \mathrm{pEDA}, \mathrm{pDETA}$, and pTEPA. However, a direct comparison of all polymers on a per gram basis is problematic, since the molecular weight of the
Table 2. Uranyl Capacities Expressed in Terms of mg U/ $\mathrm{g}_{\text {polymer }}$ and $\mathrm{mmolU} / \mathrm{mol}_{\text {ligand }}{ }^{a}$

$\begin{array}{lccc}\text { resin } & \begin{array}{c}\mathrm{U} \text { capacity }(\mathrm{mg} \mathrm{U} / \\ \left.\mathrm{g}_{\text {polymer }}\right)\end{array} & \begin{array}{c}\mathrm{N} \text { capacity } \\ \left(\mathrm{mmol} \mathrm{N} / \mathrm{g}_{\text {polymer }}\right)\end{array} & \begin{array}{c}\mathrm{U} \text { capacity (mmol } \\ \left.\mathrm{U} / \text { mol }_{\text {ligand }}\right)\end{array} \\ \text { pVBC } & 0 & & 0 \\ \text { pDMA } & 0.09 & 4.48 & 0.084 \\ \text { pMA } & 0.14 & 3.60 & 0.165 \\ \text { pPIP } & 0.97 & 5.30 & 1.54 \\ \text { pDAP } & 6.05 & 5.56 & 9.14 \\ \text { pDAB } & 6.62 & 5.81 & 9.57 \\ \text { pA } & 14.8 & 5.46 & 11.4 \\ \text { pEDA } & 10.4 & 6.61 & 13.2 \\ \text { pDETA } & 8.89 & 8.43 & 13.3 \\ \text { pTEPA } & 7.17 & 8.51 & 17.7 \\ \text { pTAEA } & 6.78 & 7.10 & 16.0\end{array}$

${ }^{a}$ All runs performed in duplicate, and capacities $(\mathrm{mg} \mathrm{U} / \mathrm{g}$ ) are reproducible to $\pm 5 \%$.

monomer unit changes as the ligand structure changes. A comparison on the basis of the nitrogen capacity is more useful. Converting $\mathrm{mg} \mathrm{U} / \mathrm{g}_{\text {polymer }}$ to $\mathrm{mmol} \mathrm{U} / \mathrm{mol}_{\text {ligand }}$ allows for a more meaningful comparison of the ligands' inherent affinities on a molar basis. Table 2 reports the affinities on a per-gram and per-mole basis in order to indicate that high affinities are achieved with relatively low-mass ligands (a high-affinity ligand coupled to a high-mass ligand is not useful, since the final polymer to be deployed must be of low total weight). The results in Table 2 underscore the significance of the primary amine to the removal of uranium from seawater. The $\mathrm{pA}$ value is still high $\left(11.4 \mathrm{mmol} \mathrm{U} / \mathrm{mol}_{\text {ligand }}\right)$ while $\mathrm{pDAP}$ and $\mathrm{pDAB}$ 
have comparable and only somewhat lower values (9.14 and $9.57 \mathrm{mmol} \mathrm{U} / \mathrm{mol}_{\text {ligand, }}$ respectively). pEDA and pDETA are now seen to have the same capacities (13.2 and $13.3 \mathrm{mmol} \mathrm{U} /$ $\mathrm{mol}_{\text {ligand }}$ respectively). pTEPA has a still higher value (17.7 $\left.\mathrm{mmol} \mathrm{U} / \mathrm{mol}_{\text {ligand }}\right)$ that is almost equivalent to pTAEA (16.0 $\left.\mathrm{mmol} \mathrm{U} / \mathrm{mol}_{\text {ligand }}\right)$. The results are consistent with the primary amine having a high affinity for the uranyl ion from seawater: TEPA immobilization occurs, to some extent, through one of the interior nitrogens, giving two primary amines per ligand while TAEA inevitably gives two primary amines per ligand. (A statistical analysis of the substitution reaction supports this thesis and will be reported.)

Comparison with Amidoxime. It is relevant to compare the results reported in Table 2 with the amidoxime ligand in order to gauge the relative affinities of the primary amine and amidoxime ligands. The highest capacity attained for the amidoxime from seawater is $4 \mathrm{mg} \mathrm{U} / \mathrm{g}_{\text {polymer }}$ with the ligand on polyethylene fibers. ${ }^{22}$ A comparison with pA (14.8 mg U/ $\left.\mathrm{g}_{\text {polymer }}\right)$ is problematic, however, because of the higher monomer molecular weight for the latter and the difference in initial solution uranyl levels (actual seawater in the former, spiked artificial seawater in the latter for analytical purposes). A more valid comparison would be between the values in Table 2 with amidoxime bound to the same polymer support and the same initial solution conditions. While the monoamidoxime is difficult to prepare on polystyrene, the diamidoxime has been prepared (Figure 2). It has a uranyl capacity of $2.34 \mathrm{mg} \mathrm{U} /$

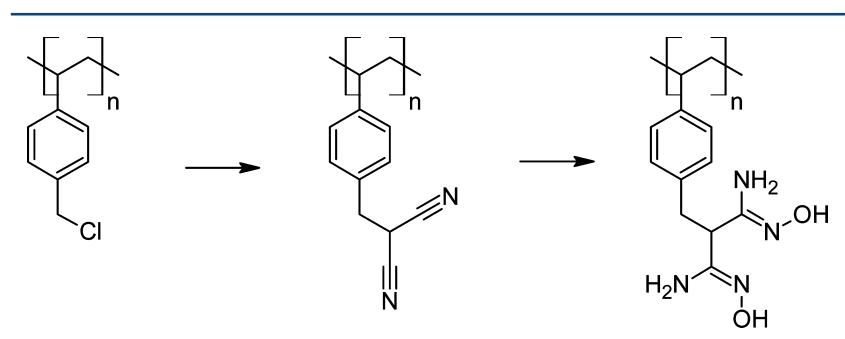

Figure 2. Polystyrene-bound diamidoxime prepared from immobilized malononitrile.

g polymer. With a nitrogen capacity of $10.4 \mathrm{mmol} / \mathrm{g}$, this recalculates to $3.79 \mathrm{mmol} \mathrm{U} / \mathrm{mol}_{\text {ligand. }}$. Since the diamidoxime has a higher uranyl affinity than the monoamidoxime, ${ }^{23}$ the results reported here with $\mathrm{pA}$ suggest at least a 3 -fold increase in uranyl capacity by the primary amine ligand (calculated on a mole basis) and a 4-fold increase when ligands with two primary amines per ligand are utilized.

Binding Mechanism. The binding mechanism must account for the significantly higher affinity of the primary amine, relative to secondary and tertiary amines. The conditions in seawater are such that the uranyl species are primarily $\mathrm{UO}_{2}\left(\mathrm{CO}_{3}\right)_{2}{ }^{2-}$ and $\mathrm{UO}_{2}\left(\mathrm{CO}_{3}\right)_{3}{ }^{4-24}$ and that they exist mostly as the calcium salt. ${ }^{25}$ The amines are protonated at seawater $\mathrm{pH}$ with chloride as the counterions. ${ }^{26}$ Given these conditions, it is proposed that the sorption mechanism is one of cation exchange at the uranyl species (Figure 3).

An analogous reaction is the formation as a precipitate of ammonium uranyl carbonate from the combination of ammonium and uranyl carbonate ions (eq 1). ${ }^{1}$

$$
4 \mathrm{NH}_{4}^{+}+\left[\mathrm{UO}_{2}\left(\mathrm{CO}_{3}\right)_{3}\right]_{\text {sol }}^{4-} \rightarrow\left[\mathrm{NH}_{4}\right]_{4}\left[\mathrm{UO}_{2}\left(\mathrm{CO}_{3}\right)_{3}\right]_{s}
$$

In the present case, the binding site is the carbonate ion as the ammonium ion exchanges with the calcium. Carbonate is a hard anion ${ }^{27}$ and the exchange requires ammonium $\left(-\mathrm{NH}_{3}^{+}\right)$ to be harder than calcium. This is supported by the observation that the $\mathrm{NH}_{4}^{+}$ion exchanges onto aluminosilicates in preference to $\mathrm{Ca}^{2+}, \mathrm{Mg}^{2+}$, and $\mathrm{K}^{+}{ }^{28}$ Consideration of the hard-soft aspect of the exchange is also consistent with the absence of significant activity by the secondary and tertiary amines: increasing the organophilicity at the nitrogen increases the softness of the ammonium ligand ${ }^{29}$ and thus decreases their affinity for the hard carbonate complex.

An alternative to the cation exchange mechanism is sorption by a coordination mechanism. While it is unlikely that six primary amine ligands can replace the three carbonate ions due to steric factors, substitution of one carbonate for two primary amines is reasonable (Figure 4) with electroneutrality maintained by the $\mathrm{Cl}^{-}$ions originally present on the amine. This is consistent with the fact that pPIP has some affinity, albeit low. Research is underway to determine whether this occurs, at least to some extent, especially as the contact time is increased.

The binding of the primary amine to the uranyl ion may shed light on the mechanism by which the amidoxime operates. It is tempting to propose that the amidoxime mechanism is a sum of two elementary coordinative stabilizations: one from the $-\mathrm{NH}_{2}$, and the other from the $-\mathrm{NHOH}$. However, the literature suggests otherwise. However, the literature suggests otherwise and the mechanism proposed here is consistent with it. Density functional theory (DFT) calculations indicate that the uranyl binds to the amidoxime in an $\eta^{2}$ motif through a deprotonated oxygen and the nitrogen to which the oxygen is bonded. ${ }^{30}$ The calculations do not show that the primary amine enters into the binding. The calculated structure is supported by crystal structures of the uranyl ion bound to acetamidoximate and benzamidoximate (the crystals having been grown from uranyl nitrate in a methanolic $\mathrm{CH}_{3} \mathrm{NO}_{2}$ solution). The $\eta^{2}$ motif is also supported by crystals grown from uranyl nitrate in methanol and $N$-methyl-N-(2-(amidoximate)-ethyl)imidazolium bis(trifluoromethane)sulfonamide. ${ }^{31}$ While the carbonate ion was not part of the calculations nor in the crystal growth, the results are still consistent with the hypothesis that the amine binds to the uranyl carbonate through an exchange of the hard calcium ion by the harder ammonium ion: in the amidoxime, the electron-withdrawing ability of the primary amine creates a hard site at the deprotonated oxygen to which the uranyl binds while the

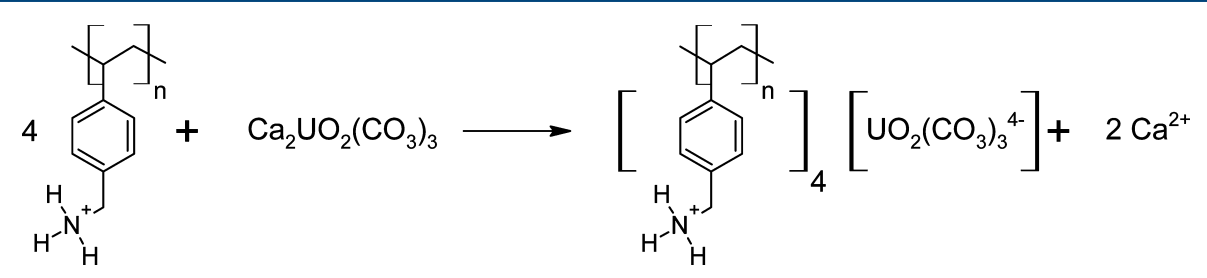

Figure 3. Sorption of uranyl from seawater by the primary amine by cation exchange at the uranyl species. 


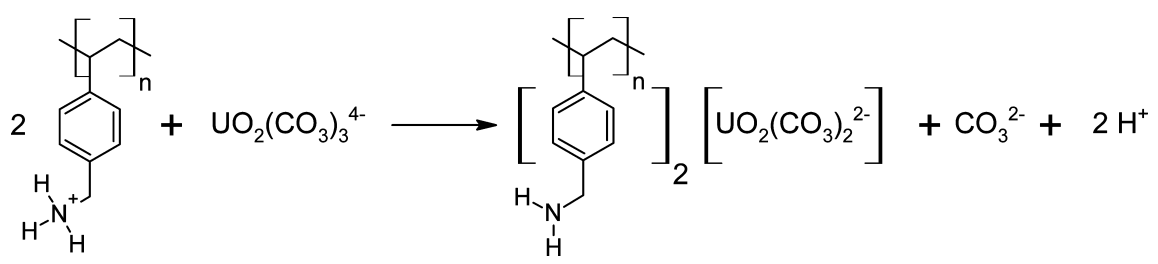

Figure 4. Sorption of uranyl from seawater by the primary amine by coordination at the uranyl.

primary amine, bound to a $\mathrm{C}=\mathrm{N}$, is delocalized through the $\pi$ orbitals and so loses its hardness and is unable to bind the uranyl. Although the presence of the carbonate ion may change the conclusions from both the DFT calculations and the crystal structure, it is interesting that the hard-soft explanation holds, even with the amidoxime results reported in the literature.

\section{CONCLUSIONS}

The primary amine is found to have a dominant effect on the sorption of uranyl from seawater. This could become important in the preparation of sorbents with high uranyl capacities under seawater conditions. The extent of complex formation is limited by the decreasing probability of formation as molecularity increases. Such a limitation could be overcome by immobilizing ligands with a high density of primary amine sites. Mobility of the primary amine sites also appears crucial to allow the formation of the corresponding complexes around the equatorial plane of the uranyl cation or carbonate complex.

Current research is focused on increasing the uranyl capacity by increasing the primary amine density on new ligand structures involving pentaerythritol as a scaffold, as well as immobilizing amines on polypropylene fiber.

\section{AUTHOR INFORMATION}

\section{Corresponding Author}

*E-mail: alexsd@hunter.cuny.edu.

\section{Notes}

The authors declare no competing financial interest.

\section{ACKNOWLEDGMENTS}

We gratefully acknowledge funding from the U.S. Department of Energy through Contract No. 120542 from the Nuclear Energy University Program administered by Battelle Energy Alliance, LLC. We thank Ms. Laura A. Oliveira for preparing the polymers with the EDA, DETA, and TEPA ligands. We also thank Drs. Ben Hay, Costas Tsouris, and Chris Janke at the Oak Ridge National Laboratory for useful discussions.

\section{REFERENCES}

(1) Gupta, C. K.; Singh, H. Uranium Resource Processing: Secondary Resources; Springer: Berlin, New York, 2003.

(2) Berto, S.; Crea, F.; Daniele, P. G.; Gianguzza, A.; Pettignano, A.; Sammartano, S. Advances in the investigation of dioxouranium(VI) complexes of interest for natural fluids. Coord. Chem. Rev. 2012, 256, 63-81.

(3) Zhu, X.; Alexandratos, S. D. Unpublished results.

(4) Marion, G. M.; Millero, F. J.; Camoes, M. F.; Spitzer, P.; Feistel, R.; Chen, C. T. A. pH of seawater. Mar. Chem. 2011, 126, 89-96.

(5) Astheimer, L.; Schenk, H. J.; Witte, E. G.; Schwochau, K. Development of sorbers for the recovery of uranium from seawater. 2 . The accumulation of uranium from seawater by resins containing amidoxime and imidoxime functional groups. Sep. Sci. Technol. 1983, $18,307-339$.

(6) Schenk, H. J.; Astheimer, L.; Witte, E. G.; Schwochau, K. Development of sorbers for the recovery of uranium from seawater. 1 .
Assessment of key parameters and screening studies of sorber materials. Sep. Sci. Technol. 1982, 17, 1293-1308.

(7) Vukovic, S.; Watson, L. A.; Kang, S. O.; Custelcean, R.; Hay, B. P. How Amidoximate Binds the Uranyl Cation. Inorg. Chem. 2012, 51, 3855-3859.

(8) Tbal, H.; Morcellet, J.; Delporte, M.; Morcellet, M. Uranium absorption by chelating resins containing amino groups. J. Macromol. Sci., Pure Appl. Chem. 1992, A29, 699-710.

(9) Rivas, B. L.; Maturana, H. A.; Angne, U.; Catalan, R. E.; Perich, I. M. Resins with retention properties for heavy metals. Part 4. Polym. Bull. 1986, 16, 305-309.

(10) Rivas, B. L.; Maturana, H. A.; Bartulin, J.; Catalan, R. E.; Perich, I. M. Poly(ethylenimine) supports for resins with retention properties for heavy metals. Part 3. Polym. Bull. 1986, 16, 299-303.

(11) Rivas, B. L.; Maturana, H. A.; Perich, I. M.; Angne, U. Polyethylenimine supports for resins with retention properties for heavy metals. Part 1. Polym. Bull. 1985, 14, 239-243.

(12) Rivas, B. L.; Maturana, H. A.; Perich, I. M.; Angne, U. Linear polyethyleneimine supports for resins with retention properties for heavy metals. Part 2. Polym. Bull. 1986, 15, 121-125.

(13) Kobayashi, S.; Tanabe, T.; Saegusa, T.; Mashio, F. Phosphonomethylated polyethylenimine resin for recovery of uranium from seawater. Polym. Bull. 1986, 15, 7-12.

(14) Kobayashi, S.; Tokunoh, M.; Saegusa, T.; Mashio, F. Poly(allylamine). Chelating properties and resins for uranium recovery from seawater. Macromolecules 1985, 18, 2357-2361.

(15) Crea, F.; Gianguzza, A.; Pettignano, A.; Sammartano, S. Interactions of Dioxouranium(VI) with Polyamines in Aqueous Solution. J. Chem. Eng. Data 2010, 55, 3044-3050.

(16) Parkin, F. R. Comprehensive Coordination Chemistry II, Vol. 3: Coordination Chemistry of the s, p, and $\mathrm{f}$ Metals; Elsevier, Ltd.: Amsterdam, 2004; p 629.

(17) ASTM International, Standard Practice for the Preparation of Substitute Ocean Water, Designation: D1141-98 (Reapproved 2003).

(18) Yang, Y.; Alexandratos, S. D. Mechanism of Ionic Recognition by Polymer-Supported Reagents: Immobilized Tetramethylmalonamide and the Complexation of Lanthanide Ions. Inorg. Chem. 2010, 49, $1008-1016$.

(19) Zhu, X.; Alexandratos, S. D. Polystyrene-Supported Amines: Affinity for Mercury(II) as a Function of the Pendant Groups and the $\mathrm{Hg}$ (II) Counterion. Ind. Eng. Chem. Res. 2005, 44, 8605-8610.

(20) Vaquero, J. J.; Fuentes, L.; Del Castillo, J. C.; Perez, M. I.; Garcia, J. L.; Soto, J. L. The Reactions of Benzylmalononitriles with Hydrazine and Hydroxylamine. Synthesis of Pyrazoles, Isoxazoles, and Pyrazolo[1,5-a]-pyrimidine Derivatives. Synthesis 1987, 1987, 33-35.

(21) Loadman, M. J. R., Analysis of Rubber and Rubber-Like Polymers; Kluwer Academic Publishers: Dordrecht, 1998.

(22) Kim, J.; Oyola, Y.; Mayes, R.; Janke, C.; Dai, S.; Tsouris, C. Testing of Amidoxime-Based Adsorbent for the Recovery of Uranium From Seawater. Presented at the 2012 AIChE Annual Meeting, Pittsburgh, PA, Oct. 28-Nov. 2, 2012, Paper No. 277098.

(23) Kavakli, P.; Seko, N.; Tamada, M.; Goven, O. A Highly Efficient Chelating Polymer for the Adsorption of Uranyl and Vanadyl Ions at Low Concentrations. Adsorption 2005, 10, 309-315.

(24) Pashalidis, I.; Czerwinski, K. R.; Fanghanel, T.; Kim, J. I. Solidliquid phase equilibria of $\mathrm{Pu}(\mathrm{VI})$ and $\mathrm{U}(\mathrm{VI})$ in aqueous carbonate systems. Determination of stability constants. Radiochim. Acta 1997, $76,55-62$. 
(25) Dong, W.; Brooks, S. C. Determination of the Formation Constants of Ternary Complexes of Uranyl and Carbonate with Alkaline Earth Metals $\left(\mathrm{Mg}^{2+}, \mathrm{Ca}^{2+}, \mathrm{Sr}^{2+}\right.$, and $\left.\mathrm{Ba}^{2+}\right)$ Using Anion Exchange Method. Environ. Sci. Technol. 2006, 40, 4689-4695.

(26) Smith, R. M.; Martell, A. E. Critical Stability Constants, Vol. 2: Amines; Plenum Press: New York, 1975; p 415.

(27) Martin, R. B. Practical hardness scales for metal ion complexes. Inorg. Chim. Acta 2002, 339, 27-33.

(28) Weatherley, L. R.; Miladinovic, N. D. Comparison of the ion exchange uptake of ammonium ion onto New Zealand clinoptilolite and mordenite. Water Res. 2004, 38, 4305-4312.

(29) Bonnesen, P. V.; Brown, G. M.; Alexandratos, S. D.; Bavoux, L. B.; Presley, D. J.; Patel, V.; Ober, R.; Moyer, B. A. Development of Bifunctional Anion-Exchange Resins with Improved Selectivity and Sorptive Kinetics for Pertechnetate: Batch-Equilibrium Experiments. Environ. Sci. Technol. 2000, 34, 3761-3766.

(30) Vukovic, S.; Watson, L. A.; Kang, S. O.; Custelcean, R.; Hay, B. P. How Amidoximate Binds the Uranyl Cation. Inorg. Chem. 2012, 51, 3855-3859.

(31) Barber, P. S.; Kelley, S. P.; Rogers, R. D. Highly selective extraction of the uranyl ion with hydrophobic amidoxime-functionalized ionic liquids via $\eta^{2}$ coordination. RSC Adv. 2012, 2, 8526-8530. 